\title{
"Primus inter Pares"?-The Perception of Emergent Leadership Behavior in Agile Software Development Teams
}

\author{
Jan Biehler \\ Technical University of Munich \\ jan.biehler@tum.de
}

\author{
Leonard Przybilla \\ Technical University of Munich \\ leonard.przybilla@tum.de
}

\author{
Helmut Krcmar \\ Technical University of Munich \\ helmut.krcmar@tum.de
}

\begin{abstract}
Despite being a key feature of Agile Software Development $(A S D)$, self-organization within ASD teams has received limited research attention. Hence, this study furthers our understanding of how informal emergent leadership may develop within ASD teams by combining knowledge on ASD teams with extant research on emergent leadership. In an exploratory mixed-method study of two Scrum teams, we observed two specific types of emergent leaders, namely, a "detail-oriented structurer", and a "big picture coordinator." For emergent leadership to develop, the Scrum master had to create a "leadership gap." Given this leadership gap, emergent leadership may develop in a circular manner: specific behaviors of team members and their perceptions may provide the basis for emergent leadership, which combined with implicit leadership theories of team members give rise to a leadership structure. Our results add to research on emergent leadership and increase our understanding of self-organization in ASD teams.
\end{abstract}

\section{Introduction}

With the emphasis on self-organization in agile software development (ASD) teams as a central success factor of agile methodology, the Agile Manifesto proclaims a paradigmatic break with traditional hierarchical team conceptions based on topdown leadership [1]. However, as experiences from leaderless approaches to organization show, intentional formal absence of leadership can degenerate into a "tyranny of structurelessness" informal leadership may not be accepted within the team, jeopardizing team cohesion and success [2].

However, practice indicates a better performance of ASD teams compared with traditional software development (SD) teams [3]. ASD teams appear to effectively balance the extremes of rigid formal structures and informal structurelessness in their selforganization. Research on how ASD teams selforganize in practice is, however, scarce.

One ordering factor in this regard may be the emergence of informal leaders in ASD teams [4], who develop without a formal assignment within the team and are accepted by team members [5]. This notion extends descriptive insights into the organization of team collaboration, and leader-like behavior of group members in ASD teams [6,7].

Research on teams, in general, indicates that emergent leadership, that is, group members exert significant influence on other group members without holding formal authority [8], occurs in self-organized groups as a dominant informal leadership style through social interaction. Consequently, emergent leadership may increase team performance by structuring this very interaction [9]. Considering the grounds for emergence, the character traits of informal leaders, their competencies, the behavior of team members and its perception by other team members, as well as the shape of interaction within the teams are crucial [10-12].

Given extant evidence of informal leadership as a key means of self-organization in ASD teams and the known role of emergent leadership in autonomous teams, it stands to reason, an emergent leader as "primus inter pares," that is "first among equals," may develop in ASD teams. To investigate this proposition, we pose the following research question "What role does the behavior of team members in social interaction within ASD teams play for being perceived as emergent leaders?"

Linking general group research on emergent leadership with literature on self-organization in ASD we analyze group interaction in two ASD teams using a mixed-methods approach. We discuss our results especially concerning implications for ASD.

\section{Theoretical background}

\subsection{Agile self-organization}

Coinciding with observations of formal and informal leadership within and around ASD teams, research recognized that self-organization is crucial for ASD teams to react dynamically to operative issues and to constant uncertainty, which is pressing in software development (SD) environments [11, 13]. 
When describing the key role of self-organization for ASD teams, research has equally highlighted potential issues in self-organization. For example, the strategic objectives of management may only fit poorly with agile iterations [14], which may curtail the ability to self-organize. Within an ASD team, the sought-after democratic participation of members may be unduly swayed by an overly expressive team member [15]

Considering the requirements of an ASD team to be able to self-organize, research highlighted the influence of formal leadership by senior management and the Scrum master as an agile coach [16]. Although ASD methodology calls for [13], and thus arguably catalyzes, informal leadership within ASD teams, support from the senior management is crucial [6]. Compared with such propositions, there is a dearth of research on self-organization within a team [6], concerning, for example, the concrete selforganization regarding formal and informal leadership structures, including how roles within teams are claimed and granted by team members [17].

Research has, however, elucidated some aspects of team-internal self-organization. As a characteristic trait, ASD teams have high operative autonomy in task allocation and the organization of their work process $[7,18]$. This autonomy is reflected in the occurrence of informal roles as means of self-organization in ASD teams $[6,16]$. To develop effective self-organization, research highlighted the creation of a leadership gap by the Scrum master as a prerequisite [19]. That is, Scrum masters need to take on an enabling role for self-organization to allow for enough team discretion in dynamically adapting to changing requirements. Thus, shared leadership structures comprising Scrum masters and team members overtaking informal leadership tasks may develop [20].

\subsection{Emergent leadership in general group research}

Emergent leadership is an informal leadership style, where group members have a significant influence on other group members without holding formal authority. This case typically occurs in teams with a high discretion for self-organization [8].

Extant research has proposed numerous antecedents for emergent leadership to develop. General group research indicated that the formal leadership structure within and around the team shapes self-organization [21]. More precisely, a laissez-faire leadership style exerted by formal leaders, which allows for self-organization, is a precondition for the occurrence of informal leadership [22]. Selforganization is an interactional and dynamic process among team members, where leadership structures are volatile based on the interplay of formal and informal leadership roles in teams [21, 23].

For emergent leadership to develop, DeRue and Ashford propose a three-step interactional process based on team members claiming leadership roles and granting them to other team members with a behavior congruent to personal implicit leadership theories and the environment that a team is operating in [24]: In the first step of individual internalization, team members perceive the behavior of other team members and make sense of it based on their implicit leadership theories, which include experiences with former leaders and leadership structures [21]. If the perceived behavior matches the behavior of previously accepted leaders, then team members are willing to grant leadership identities [10].

In a second step, the willingness to grant a leadership identity has to match team members with the self-image of a leader in a reciprocal act of claiming a leadership identity [25]. In short, the candidate leader also has to claim a leadership identity.

If identities are reciprocated and collective support is ensured - meaning the leadership identity of a candidate is granted by multiple members - then, emergent leadership occurs in a third step. Granting and claiming leadership identities, thus, are a dynamic process. A multitude of emergent leaders could exercise leadership behavior simultaneously [21], which could create a structure of efficient selforganization that was observed within ASD teams [26].

In this interactional process, research pointed to the importance of authenticity in behavior exercised by team members who become emergent leaders [27]. The perception of leadership behavior rather than that of leadership traits thus seems central to the occurrence of emergent leadership [28].

Three complementary research strands, namely, task-based, relational-based, and change-oriented leadership behaviors, aimed to explain the occurrence of emergent leadership. However, which types of behavior are explanatory for the perception of legitimate emergent leadership behavior is still unclear because of divergent operationalization and the lack of theoretical foundation [12].

Yukl et al [29] have subsumed the strayed evidence on leader behavior in a hierarchical taxonomy: They identify the planning of short-term activities, the clarification of tasks and roles, and the monitoring of operations and performance as task behavior. Relations behavior is exercised by the provision of support and encouragement, recognition of achievements, the development of member skills and confidence, a consulting role for team members' issues and empowerment of team members to take 
initiative in problem-solving. Change behavior is identified in monitoring the external environment, proposing innovative strategies or visions, encouraging for innovative thinking and taking risks to promote necessary changes. The typology was applied in various analytical contexts to tackle divergent operationalization of leadership behavior and has proven robust yet [30].

As stated before, in many cases, there is not one emergent leader but emergent leadership is distributed in a shared leadership structure across multiple team members [14]. Considering the temporal development of emergent leadership, the perception of leadership behavior acts as a central element for the stability of emergent leadership [10]. Updated perceptions of, for example, competence may, however, lead to changes in leadership attributions [23].

\section{Theoretical understanding of perceived emergent leadership in ASD}

Combining the theory-driven contributions from general group research on emergent leadership and the descriptive insights in agile self-organization from the ASD literature allows for developing a theoretical understanding of the importance of perception of member behavior for the occurrence of emergent leadership in ASD teams: Emergent leadership may develop based on the social interaction within an ASD team, which is empowered to self-organize. When team members, whose behavior fits the implicit leadership theories and leadership perception of other team members, claim leadership roles, and others consequently grant these leadership identities, emergent leadership develops [10].

The laissez-faire leadership style of formal leaders, which general group research identified to enable informal leadership in teams [22], fits the observation of the need for the Scrum master to take on an enabling role and to create a leadership gap as a catalyst of self-organization in ASD teams [19, 31].

Conversely, the observation of ASD team members taking on multiple roles next to the formal leadership roles of the Scrum master and product owner $[6,14,20]$ is mirrored in general group research describing the shared leadership structure between emergent leaders within teams and formal leaders in the direct team environment [32, 33]. Moreover, the observation of temporal variations in informal roles that ASD team members exercise $[6,7]$ matches the theoretical understanding of emergent leadership development as a dynamic social interaction process among team members within teams [10, 24, 25].

Combining knowledge on ASD with extant insight into emergent leadership in general group research, emergent leadership in ASD teams likely occurs following the theoretical understanding of DeRue \& Ashford [24], especially since the focus on self-organization in ASD teams emphasizes interaction and face-to-face communication as central mechanisms in the occurrence of emergent leadership.

The occurrence of emergent leadership in a team in turn has effects on implicit leadership theories [21]. If such leader behavior is perceived as authentic and legitimate [27], then the individual implicit leadership theories of team members will change toward favoring communitarian leadership styles, such as emergent leadership based on collaborative self-organization instead of top-down formal authoritative leadership [21]. The former aligns well with the self-organizing bottom-up logic of ASD teams called for in [1].

\section{Research design}

Hitherto it remains unclear whether the concept of emergent leadership applies to self-organization in ASD teams and how it develops. Based on the preceding theoretical considerations, we seek to identify which type of behavior and its corresponding perception contribute to the development of emergent leadership in ASD teams. To start closing this research gap, we conducted an explorative comparative case study [34, 35] of two Scrum teams in November 2020 using a mixed-methods design consisting of interviews and questionnaires.

Team 1 is part of a German engineering company and virtualizes the Internet of Things processes for an automotive Original Equipment Manufacturer. The team was newly set up in early 2020 and consists of six Scrum team members, one Scrum master, and a product owner.

Team 2 is part of a German insurance company and continuously develops, maintains, and provides the Point-of-Sales architecture. Team 2 practices DevOps to align IT operations and SD. This team had already applied agile methods since 2010, but agile processes were dysfunctional due to the lack of backing in senior management. This changed after the agile approach was completely reset in Summer 2020 with a new Scrum master, two product owners, and eight team members.

As the qualitative part of our mixed-methods study, we conducted individual semi-structured interviews with members of both ASD teams. We chose semi-structured interviews in order to build on extant results on emergent leadership while being able to collect rich data on unexpected relationships. The interviews served two primary purposes: 1) identifying potential emergent leaders, and 2) identifying corresponding perceived leadership 
behavior. To attain these goals, we developed a semistructured interview guide based on the previously introduced indicators on leadership behavior developed by Yukl et al. in general group literature [29], which have proven robust in earlier empirical analyses on leadership behavior [30]. To capture known aspects of leadership in ASD teams, we augmented the basis provided by general group research with questions on change-oriented leadership behavior from ASD literature [36]. Due to limitations on scope, we have had to exclude the full interview guide. It is available from the authors on request.

We conducted all interviews as video conferences using Microsoft Teams. The interviews were in German and had an average duration of 30 minutes. For analysis, we recorded all interviews as video files and transcribed them in full length. In Team 1, we conducted a total of four interviews: Three with team members and one with the Scrum master. In Team 2, we conducted three interviews: Two with team members and one with the Scrum master.

Following the interviews, participants filled in an online survey about the perceived behavior of the emergent leaders they had identified in the interviews. Likert-scale questions asked for estimates of how intense behavior of emergent leaders was perceived (from 1 "never" to "5" frequent). Each indicator of leadership behavior was covered by several questions, which were developed based on the factors ascribed to a certain leader behavior indicator by Yukl et al. and Eseryel and Eseryel [29, 36]. Due to limitations on scope, we have had to exclude the questionnaire. It is available from the authors on request.

Every interviewee filled in the survey, which allowed us to compare perceptions across team members and to cross-check results. We calculated the mean of the single questions per indicator to capture the intensity of how much a respondent perceived the corresponding leader behavior. They were aggregated on team level using the mean of the perceived leader behavior intensity among all respondents per identified leader. In addition to structuring the survey responses, the indicators of leadership behavior proposed by Yukl et al. [29] and Eseryel \& Eseryel [36] also served as the coding scheme for analyzing statements in the interviews. The comparisons of survey responses across team members (see Figures 1 and 2 below) with statements in the interviews implied close alignment of qualitative and quantitative results.

\section{Findings}

The empirical observations provide evidence of emergent leadership in both teams. Analysis of the data led to the identification of two distinct types of emergent leaders: a "detail-oriented structurer" and a "big picture coordinator," see Table 1. To better understand potential differences in leader perceptions, we analyzed the leadership structure in both teams using the leadership behavior taxonomy by Yukl et al [29]. We observed a relatively similar shared leadership structure of formal and informal roles in both Scrum teams. However, the perception of this leadership structure is clearer in the more mature team of the engineering company. In addition, the role of the Scrum master seems decisive for emergent leadership to develop.

Table 1: Perceived emergent leaders

\begin{tabular}{|c|c|c|c|c|}
\hline Team & \multicolumn{2}{|c|}{$\begin{array}{l}\text { Scrum Team } 1 \\
\text { Engineering }\end{array}$} & \multicolumn{2}{|c|}{$\begin{array}{l}\text { Scrum Team } 2 \\
\text { Insurance }\end{array}$} \\
\hline $\begin{array}{l}\text { Emerg } \\
\text { ent } \\
\text { Leader }\end{array}$ & $\begin{array}{l}\text { Structurer } \\
\text { Developer } \\
\text { B }\end{array}$ & $\begin{array}{l}\text { Coordinat } \\
\text { or } \\
\text { Architect C }\end{array}$ & $\begin{array}{l}\text { Structure } \\
\mathbf{r} \\
\text { Analyst } \\
\text { AN }\end{array}$ & $\begin{array}{l}\text { Coordina } \\
\text { tor } \\
\text { Architect } \\
\text { SA }\end{array}$ \\
\hline $\begin{array}{l}\text { Perceiv } \\
\text { ed by }\end{array}$ & $\begin{array}{l}\text { Developer } \\
\text { B, } \\
\text { Architect } \\
\text { C, Tester } \\
\text { A, Scrum } \\
\text { Master } \\
\text { SMA }\end{array}$ & $\begin{array}{l}\text { Developer } \\
\text { B, } \\
\text { Architect } \\
\text { C, Scrum } \\
\text { Master } \\
\text { SMA }\end{array}$ & $\begin{array}{l}\text { Developer } \\
\text { BB, } \\
\text { Scrum } \\
\text { Master } \\
\text { SMAA }\end{array}$ & $\begin{array}{l}\text { DevOps } \\
\text { AA, } \\
\text { Developer } \\
\text { BB, } \\
\text { Scrum } \\
\text { Master } \\
\text { SMAA }\end{array}$ \\
\hline
\end{tabular}

\subsection{Emergent leader 1: Detail-oriented Structurer}

Turning toward the perceived emergent leaders, software engineer B is identified as the "detailoriented structurer" in the engineering team 1 by all study participants including the Scrum master SMA, and also in self-perception.

$\mathrm{He}$ is perceived as an operation-oriented informal leader who has overtaken duties in organizing and structuring Sprint Dailys from the Scrum master out of "self-initiative to overcome unstructured meetings" in the perception of tester A. According to Architect C, his "competence and passion" for the tasks of the team and his dissatisfaction with "messiness" qualify him for enacting leader behavior. Developer B explains the functions and goals of tasks and influences the task prioritization and coordination of team activities and task packages. His colleagues value that someone is leading through meetings, during which the Scrum master takes a more restrained role. Figure 1 details the perceptions of behavior in the engineering team 1 .

In the insurance team 2, among team members, the perception of a "detail-oriented structurer" is less clear, who also enacts divergent behavior. The analyst $\mathrm{AN}$ is perceived by developer $\mathrm{BB}$ as an emergent leader with "high expertise" who is the "role model" and the "perfect team member if one needs to draw one." Analyst AN is perceived as very encouraging, providing others with responsibility and self-esteem 
for discretion over their task completion. If consulted for help, he explains the functions and goals of tasks. According to DevOps AA, the Scrum master has an invasive role in the daily work of team 2. Analyst AN is thus mostly in the background but is always accessible if team members require detailed advice.

\subsection{Emergent leader 2: "Big Picture Coordinator"}

Turning to the perceived "big picture coordinator," again, the perception of such an informal coordinator is clearer in the engineering team 1 . The software architect $\mathrm{C}$ is perceived as a coordinationoriented emergent leader managing the "big picture" and concretizing "the concrete mission" according to the Scrum master SMA. In his self-perception, software architect $\mathrm{C}$ mirrors the role of the "product owner within the team" which is acknowledged by the other participants in the study. According to developer B, software architect C "takes on coordinative tasks" capitalizing on "years-long experience." According to tester A, software architect C also "mediates" in more confrontative discussions and functions as a "resting pole" in team interaction. Thus, he is perceived as more supportive and consulting and more relationthan task-oriented compared with developer B in the "structurer" role. Developer B perceives the supervision of external changes and threats and opportunities in the team environment and the evaluation of chances and risks as a constant behavior of C. Additionally, tester A and developer B perceive the clarification of role allocations and responsibilities per role as a behavior frequently enacted by C. Figure 1 summarizes the perceptions of behavior in the engineering team 1 .

In the insurance team 2, the software architect SA is identified as a coordination-oriented emergent leader who overtakes the behavior from the Scrum master if the latter misses Sprint meetings. Software architect SA is an experienced team member with "broad knowledge" according to the Scrum master SMAA who "is in the lead for technical topics" and who is "responsible for knowledge transfer." For developer BB, software architect SA is a leader because he has a "rougher overview," locates isolated or special tasks or roles, and positions them in their context for the team. Additionally, he is perceived as the only one monitoring external influences including threats and opportunities, and as the one who is pushing the team to react to these influences. Thus, he is perceived as a change-oriented strategist.

However, software architect SA would have also overtaken the coordination of Sprint Dailys in case the scrum master is not present. The reason is the intrinsic motivation based on dissatisfaction with disorder and "no one else wants to do it" according to developer BB. He is thus perceived as a responsible team member in a seniority position by his colleagues who also clarifies the role allocation but acts especially as a change-initiator with risk-prone, supportive and encouraging behavior. Figure 2 summarizes the perceptions of behavior in the insurance team 2 .

\subsection{Leadership structure and role of Scrum master}

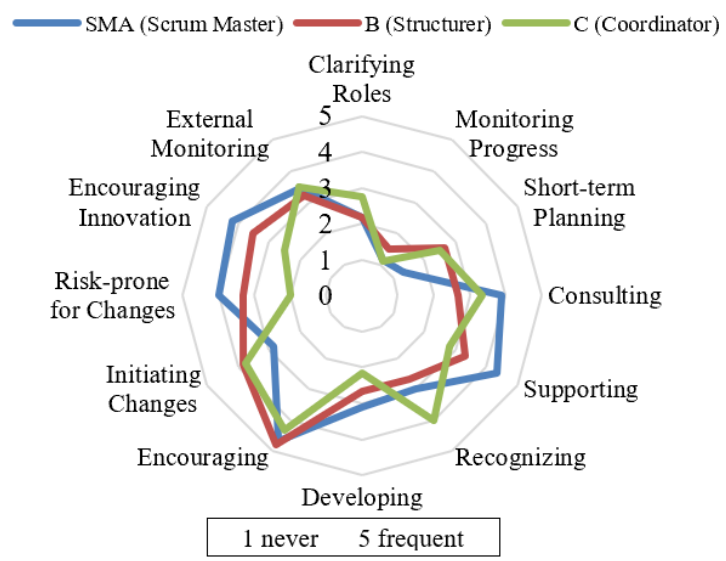

Figure 1: Perceived behavior of emergent leaders and Scrum master - engineering team Own Illustration following $[29,36]$

Although team members perceived emergent leaders in both Scrum teams, perceptions were much more pronounced in team 1 at the engineering company. This difference in perceptions highlights the role of the Scrum master in enabling emergent leadership. In our investigation, the main difference between the Scrum masters in the two teams was the level of interference with self-organization.

According to the perception of team members, the Scrum master in the engineering team 1 fulfills an enacting role by organizing scrum artifacts (Sprint Plannings, Sprint Retros, Sprint Reviews) and by spanning boundaries through interaction with coaches of other agile teams. He typically does not intervene in Sprint Dailys and only "takes a structuring function" by demanding discipline in discussions after having waited when the team did not manage to self-organize according to architect $\mathrm{C}$.

In architect C's perception, it is "very important [to have] someone with an outside view on the things we are doing." The Scrum master is perceived to be very active in enabling team members to innovative thinking (see Figure 1). He acts risk-prone for changes, mirroring the role of a change agent, is supportive and consulting, and is considered as always having an "open ear" for team members according to 
developer B. He identifies the trust of the Scrum master in the independent decision-making of the team without controlling task progress or the allocation of roles as central for allowing for self-organization.

$\longrightarrow$ SMAA (Scrum Master) $\longrightarrow$ SA (Coordinator) $\longrightarrow$ AN (Structurer)

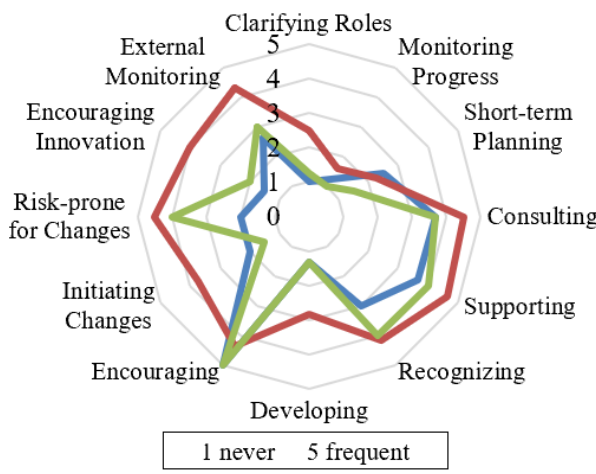

Figure 2: Perceived behavior of emergent leaders and Scrum master - insurance team Own Illustration following [29, 36]

Conversely, in the insurance team 2, the Scrum master is perceived to take a more invasive role for setting up team interaction according to the team members. He overtakes a more active role in Sprint meetings, which are thus "relatively fast and structured" according to DevOps AA. That is, he prepares and organizes Scrum procedures and is also involved in short-term planning in Sprint Dailys which he "moderates strictly." That is considered "helpful" by developer BB. However, he is also perceived to encourage the ASD team for independent decisionmaking, which should, according to DevOps AA, allow for self-organization (see Figure 2).

Although similar emergent leadership roles are identified in both teams, the degree of invasiveness by the Scrum masters on self-organization diverges. In addition, the consistency of emergent leadership behavior differs: It is more pronounced in the engineering team 1: Here, we obtained more coherent statements concerning emergent leader behavior. As a consequence, the perceptions in the engineering team point to a more communitarian leadership structure compared to the insurance team 2 .

\section{Discussion}

We drew on extant research into informal, emergent leadership to further our understanding of self-organization, which constitutes a key feature of work in ASD teams. Moreover, we focused on the behaviors of emergent leaders and the corresponding perception by teammates to explore the prevalence and development of emergent leadership in ASD teams. We found evidence of two types of emergent leaders based on interviews and questionnaires in two ASD teams, that is, a "detail-oriented structurer" and a "big picture coordinator." The former is claimed by team members who are deeply involved in detailed task processing. The latter leadership identity is claimed by software architects who integrate the bigger picture and a vision into team interaction Although the two roles emerged in both teams, a comparison between the teams highlights the key role of the Scrum master to facilitate emergent leadership and self-organization. In the following, we will discuss our results with regard to extant research on emergent leadership, to knowledge on self-organization in ASD, as well as their limitations.

\subsection{Relation to extant research on reasons for leader emergence}

In general, our theoretically-guided expectations regarding the reasons for leaders to emerge are supported. Perception plays a vital role in the development of reciprocally granted and claimed informal emergent leaders within ASD teams. Every perceived emergent leader also perceived himself as a team member exerting informal leadership functions. This character fits the theoretically modeled mechanism that the reciprocal process of both, claiming and granting leadership identity, presupposes the occurrence of emergent leadership [24].

Evidently, the overtaking of steering tasks by formally equally powerful team members is valued by others who often do not want to claim these roles for themselves. The reason is that they add additional tasks to the core operative tasks from the product backlog. In this vein, agile methodology demands more engagement of teams for self-organization without restricting how these additional tasks should be fulfilled [37]. The emergent leaders often have an intrinsic motivation for overtaking these additional tasks as particularly the detail-oriented structurers are averse to disorder.

Our observations also indicate that emergent leaders are in total not perceived as more competent than other team members but rather as more engaged in team interaction. This result contradicts earlier research identifying the differences in competencies as key for granting leadership [11]. Evidently, granting leadership identities seems to mainly rely on functional specialization, the self-motivation of emergent leaders, and the adoption of tasks in organizing and coordinating sprint dailies by team members, but less on perceived differences in competence between emergent leaders and "normal" team members.

The theoretical expectation is further supported such that the perception of emergent leaders was 
clearer in the more mature agile team 1 of the engineering company. In this team, emergent leaders were recognized clearer than those in the insurance company where the Scrum master still authoritatively led the ASD team. The engineering team was selforganized in flatter hierarchies where both emergent leaders overtook divergent leadership tasks. This case was recognized more clearly by team members. On the contrary, in the insurance team, the team members paid additional attention to the formal hierarchy regarding the team-internal allocation of leadership tasks. It stands to reason the more extensive experience in functional ASD collaboration may have already changed the implicit leadership theories of team members in the engineering company toward communitarianism [21].

\subsection{Contribution to knowledge on self- organization in ASD teams}

In addition to extending knowledge of emergent leadership in general, our results increase our understanding of self-organization in ASD teams, which is lacking in extant literature [6]. We specifically contribute to knowledge on how emergent leadership may develop in ASD teams. In the following, we will discuss the need for a leadership gap and its role in a theoretical model of leadership emergence in ASD teams, compare the observed emergent leaders with known roles in ASD teams, and discuss leader behavior observed in ASD teams with regard to extant research on teams in general. These observations in turn have implications for the functioning and performance of ASD teams.

6.2.1. Need for a pronounced leadership gap. Concerning the prerequisites for emergent leadership to develop, our observation of a pronounced leadership gap in the engineering team corroborates extant evidence on the centrality of agile coaches enabling the self-organization of agile teams [19]. In addition to extant insights, our results also indicate the invasiveness of the agile coach on team interaction and self-organization to influence the clarity of perceptions of leadership behavior by ASD team members. The clarity of leadership perceptions may subsequently affect the reciprocal process of claiming and granting leadership identities as a key contributor to emergent leadership [24]. Our results thus indicate emergent leadership to be greatly solidified and reciprocally perceived, granted and claimed if the agile coach enables the team to self-organize.

A pronounced leadership gap may subsequently affect team performance by increasing the certainty of leadership structures for team members. That is, considering that the two emergent leaders took over all relevant functions, the Scrum team of the engineering company was fully operational in daily work without the Scrum master. On the contrary, the Scrum team of the insurance company would be only operational concerning very specific areas and tasks without the Scrum master. We suggest that the reason may be the high invasiveness of the Scrum master in the set-up stage of the self-organization of the team. This interpretation is supported by the admission of Scrum master SMAA that he needs to withdraw from various leadership behaviors.

6.2.2. Theoretical model of leader emergence in ASD. Combining these considerations on the leadership gap with the empirical analysis and the theoretical model of DeRue and Ashford [24], see also section 2.2, our results imply that emergent leadership occurs in ASD teams through a reinforcing circle with a distinct starting point. In addition to leadership structure, implicit leadership theories, and the claiming and granting of leadership identities, which are driven by the perception of the behavior of emergent leadership candidates, giving rise to emergent leadership [21, 24], our results imply a leadership gap allowing for self-organization [19] to be a crucial antecedent of emergent leadership. Figure 3 illustrates the extended theoretical model.

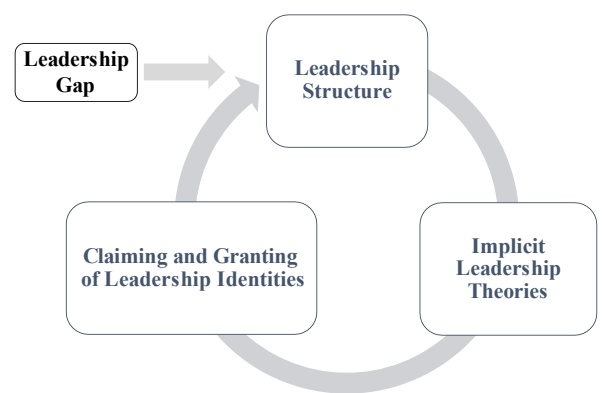

Figure 3: Theoretical model of emergent leadership occurrence built on DeRue and Ashford [24] Own Illustration

This extended theoretical model fits our observations as follows: The broader leadership gap in the engineering team 1 may create a more communitarian leadership structure and corresponding implicit leadership theories. Team members may thus be more open to claim leadership identities and others more open to granting those identities because the leadership structure allows for self-organization and catalyzes communitarian interaction. Conversely, the invasive Scrum master of the insurance team 2 solidifies a more hierarchical leadership structure translating into hierarchical implicit leadership theories and less clarity in claiming and granting leadership identities because there is less room for self-organization. Thus, this reinforcing mechanism 
explains differences in the perception of emergent leader (behavior) in both teams.

6.2.3. Emergent leaders and self-organization roles. Although we focused on the perception of informal, emergent leadership, our research relates to extant knowledge on self-organizing roles in ASD teams [6]. Several elements of the roles we observed seem analogous to the self-organizing roles described by Hoda et al. [6]. A detail-oriented structurer shares traits with the Mentor, Coordinator, and arguably Translator roles [6]. The detail-oriented structurer may help with sustaining ASD practices in the team, which is close to the Mentor role [6], by acting as a "role model," which was observed in the insurance team. Reports of the detail-oriented structurer explaining engineering tasks relate to the clarification role of a Coordinator [6] and arguably extend to the Translator role mediating between customers and team processes [6].

The observed "big picture coordinator" similarly seems to be conceptually close to the Coordinator and Translator roles. The "big picture coordinator" helps to clarify customer requirements as a Coordinator trait [6] by clarifying the role allocation and monitoring the external environment. Considering the connotation of "transferring knowledge," the "big picture coordinator" arguably relates to the Translator role [6]. The latter argument highlights, however, a key discrepancy between the emergent leadership roles that we observed and the self-organizing roles described by Hoda et al. [6]. By contrast, the roles described by Hoda et al. [6] in many instances seem to focus on helping the team interact with external entities, for example, customers or management. The roles observed in this research focus more on selforganization within the ASD teams. This discrepancy may be explained by our focus on determining perceived leadership, which team members may have attributed to a more managerial role. To further our understanding of self-organization in ASD teams, consciously differentiating the external vs. internal orientation of roles and activities may be fruitful.

6.2.4. Leader behavior in ASD teams. Given the very special work environment, the types of leader behavior in ASD teams may differ from the theoretical categorization in general group research proposed by Yukl et al [29]. Specifically, agile task-based leader behavior seems to differ from general leader behavior: The monitoring of task progress seems to be less relevant in the agile context, see figures 1 and 2 , because the agile methodology, which granularizes work in small artifacts, replaces hierarchical progress control with individual self-organization.

Similarly, some indicators proposed by Yukl et al [29] as relations-based seem to be rather task-based in the agile context: Encouraging and consulting behavior was perceived as an intense leader behavior in both teams. This behavior may, however, be rather task-based than relations-based in the agile context since the encouragement for self-initiative is a prerequisite for functional self-organization and task processing in ASD teams [38]. Especially the emergent leaders in the engineering team 1 are perceived as leading in this vein.

Also, monitoring of the external environment may in the ASD context rather be a task-based than a change-based behavior since it may predominantly comprise functional gatekeeper roles to other agile teams, which is a prerequisite for an effective processing of tasks [26].

Summarizing our empirical observations, in the agile context, task-based leader behavior may broadly encompass the clarification of roles, the encouragement of team members for self-initiative, short-term planning, and monitoring of the external environment. Relations-based behavior may consist of the support and recognition of team members as well as the development of their skills and competencies. Change-based behavior may include the initiation of changes, risk-openness for changes and the encouragement for innovative thinking. Although our exploratory empirical observations imply this structure, adjusting the theoretical categorization of leader behavior to the ASD context requires further conceptual and empirical research, for example, longterm ethnographic observations of ASD teams.

6.2.5. Emergent leadership as a theoretical lens. The preceding discussions imply emergent leadership may provide a useful theoretical lens for understanding work in ASD teams. Fulfilling the proposition to follow a theory-backed approach to research in ASD [39], the observed circle integrating the ASD-specific role of the Scrum master into the emergence of leadership, which translates to a specific leadership structure, rests on established results from general teams research. Although we provided initial results, future research into each of these areas and their interaction seems fruitful. For example, knowledge on specifics of the leadership structure may help in furthering research on shared decision-making in ASD, which may suffer from undue influence by single team members [15].

6.2.6. Practical Implications. In addition to contributing to research on ASD and opening avenues for future endeavors, our results also have practical implications. Knowledge of the existence of emergent leadership and its characteristics may provide helpful clues that can effectively promote team processes and the performance of ASD teams. From a long-term perspective, such knowledge may provide the basis for 
developing new tools or ASD practices to purposefully embrace emergent leadership as a type of informal, team-based leadership.

\subsection{Limitations and Future Research}

Our results are, however, subject to limitations. First, our study relies on data from a limited sample of team members from two agile teams with relatively similar characteristics. For example, both teams in the sample are not part of the software industry but are set in other industries. Our results may thus not generalize to other settings. Moreover, the limited sample may not have allowed for neither a more fine-grained distinction between the two types of emergent leadership we identified, nor the identification of potential additional types of emergent leadership.

Future research could incorporate a more complete sample of team members from a larger number of ASD teams with more heterogeneous characteristics. To further explore perceived emergent leader behavior, the approach of coding semistructured interviews based on theoretical models could be complemented by more open-ended interview designs. To corroborate and extend our understanding of leadership emergence, incorporating team building theories such as Tuckman's stages of group development [40] seems a fruitful approach. This may allow for understanding the co-evoluation of team characteristics and leadership. Including additional factors such as team age or the competence of team members, which extant research has proposed [21, 23], may similarly increase explanatory power. As a further extension, integrating knowledge on the effects of diversity in OT work, e.g. [41], may be fruitful. Furthering the discussion of analogies between our observations and the roles described by Hoda et al. [6], future research on roles in selforganization may benefit from precisely differentiating activities and roles based on their internal vs. external focus.

\section{Conclusion}

This study contributes towards understanding emergent leadership in ASD teams through an exploratory investigation of the type of behavior emergent leaders exercise and how team members perceive these behaviors. Studying members of two Scrum teams, we found emergent leaders to act as a "detail-oriented structurer" or a "big picture coordinator." Integrating empirical observations with established theory, the resulting circular model emphasizes the importance of creating a leadership gap by the Scrum master for the development of emergent leadership in ASD teams. Thus, this work contributes to knowledge how the agile postulate of leaderless self-organization may play out in day-today work in ASD teams.

\section{References}

[1] Beck, K., M. Beedle, A. van Bennekum, A. Cockburn, W. Cunningham, M. Fowler, J. Grenning, J. Highsmith, A. Hunt, R. Jeffries, J. Kern, B. Marick, R.C. Martin, S. Mellor, K. Schwaber, J. Sutherland, and D. Thomas, Manifesto for Agile Software Development, 2001.

[2] Freeman, J., "The Tyranny of Structurelessness", Berkely Journal of Sociology, 17, 1972, pp. 151-164.

[3] Chow, T. and D.-B. Cao, "A survey study of critical success factors in agile software projects", Journal of Systems and Software, 81(6), 2008, pp. 961-971.

[4] Przybilla, L., M. Wiesche, and H. Krcmar, "Emergent Leadership in Agile Teams- An Initial Exploration", in Proceedings of the 2019 on Computers and People Research Conference, SIGMIS-CPR, Editor. 2019.

[5] Parker, D.W., M. Holesgrove, and R. Pathak, "Improving productivity with self-organised teams and agile leadership", International Journal of Productivity and Performance Management, 64(1), 2015, pp. 112128.

[6] Hoda, R., J. Noble, and S. Marshall, "Self-Organizing Roles on Agile Software Development Teams", IEEE Transactions on Software Engineering, 39(3), 2013, pp. $422-444$.

[7] Moe, N.B., T. Dingsøyr, and T. Dybå, "Understanding Self-Organizing Teams in Agile Software Development", in 19th Australian Conference on Software Engineering (aswec 2008), Perth, Australia, 26.03.2008-28.03.2008. IEEE.

[8] Schneier, C.E. and J.R. Goktepe, "Issues in emergent leadership: The contingency model of leadership, leader sex, leader behavior", Small groups and social interaction, 1, 1983, pp. 413-421.

[9] Taggar, S., R. Hackew, and S. Saha, "Leadership Emergence in Autonomous Work Teams: Antecedents and Outcomes", Personnel Psychology, 52(4), 1999, pp. 899-926.

[10] DeRue, D.S., S.J. Ashford, and N.C. Cotton, "Assuming the mantle: Unpacking the process by which individuals internalize a leader identity", in Exploring Positive Identities and Organizations, L.M. Roberts and J.E. Dutton, Editors. 2009. Taylor \& Francis: New York.

[11] Drury-Grogan, M.L. and O. O'Dwyer, "An Investigation of the Decision-Making Process in Agile Teams", International Journal of Information Technology \& Decision Making, 12(06), 2013, pp. 1097-1120.

[12] Paunova, M., "The emergence of individual and collective leadership in task groups: A matter of achievement and ascription", The Leadership Quarterly, 26(6), 2015, pp. 935-957. 
[13] Stray, V., N.B. Moe, and R. Hoda, "Autonomous agile teams", in Proceedings of the 19th International Conference on Agile Software Development Companion - XP '18, A. Aguiar, Editor, the 19th International Conference, Porto, Portugal, 21.05.2018 - 25.05.2018. 2018. ACM Press: New York, New York, USA.

[14] Moe, N.B., A. Aurum, and T. Dybå, "Challenges of shared decision-making: A multiple case study of agile software development", Information and Software Technology, 54(8), 2012, pp. 853-865.

[15] Drury-Grogan, M.L., K. Conboy, and T. Acton, "Examining decision characteristics \& challenges for agile software development", Journal of Systems and Software, 131, 2017, pp. 248-265.

[16] Hoda, R., Self-Organizing Agile Teams: A Grounded Theory, Wellington, 2011.

[17] Hoda, R., N. Salleh, J. Grundy, and H.M. Tee, "Systematic literature reviews in agile software development: A tertiary study", Information and Software Technology, 85, 2017, pp. 60-70.

[18] Tessem, B., "Individual empowerment of agile and non-agile software developers in small teams", Information and Software Technology, 56(8), 2014, pp. 873-889.

[19] Spiegler, S.V., C. Heinecke, and S. Wagner, "Leadership Gap in Agile Teams: How Teams and Scrum Masters Mature", in Agile Processes in Software Engineering and Extreme Programming, P. Kruchten, S. Fraser, and F. Coallier, Editors. 2019. Springer International Publishing: Cham.

[20] Srivastava, P. and S. Jain, "A leadership framework for distributed self-organized scrum teams", Team Performance Management: An International Journal, 23(5/6), 2017, pp. 293-314.

[21] Wellman, N., "Authority or Community? A Relational Models Theory of Group-Level Leadership Emergence", Academy of Management Review, 42(4), 2017, pp. 596-617.

[22] Wellman, N., D.W. Newton, D. Wang, W. Wei, D.A. Waldman, and J.A. LePine, "Meeting the need or falling in line? The effect of laissez-faire formal leaders on informal leadership", Personnel Psychology, 72(3), 2019, pp. 337-359.

[23] Cook, A., B. Meyer, C. Gockel, and A. Zill, "Adapting Leadership Perceptions Across Tasks: Micro-Origins of Informal Leadership Transitions", Small Group Research, 50(2), 2019, pp. 227-265.

[24] DeRue, D.S. and S.J. Ashford, "Who will Lead and Who will Follow? A Social Process of Leadership Identity Construction in Organizations", Academy of Management Review, 35(4), 2010, pp. 627-647.

[25] DeRue, D.S., J.D. Nahrgang, and S.J. Ashford, "Interpersonal Perceptions and the Emergence of Leadership Structures in Groups: A Network Perspective", Organization Science, 26(4), 2015, pp. 1192-1209.

[26] Moe, N.B., T. Dingsøyr, and T. Dybå, "A teamwork model for understanding an agile team: A case study of a Scrum project", Information and Software Technology, 52(5), 2010, pp. 480-491.
[27] Pielstick, C.D., "Formal vs. Informal Leading: A Comparative Analysis", Journal of Leadership Studies, 7(3), 2000, pp. 99-114

[28] Acton, B.P., R.J. Foti, R.G. Lord, and J.A. Gladfelter, "Putting emergence back in leadership emergence: A dynamic, multilevel, process-oriented framework", The Leadership Quarterly, 30(1), 2019, pp. 145-164.

[29] Yukl, G., A. Gordon, and T. Taber, "A Hierarchical Taxonomy of Leadership Behavior: Integrating a Half Century of Behavior Research", Journal of Leadership \& Organizational Studies, 9(1), 2002, pp. 15-32.

[30] Behrendt, P., S. Matz, and A.S. Göritz, "An integrative model of leadership behavior", The Leadership Quarterly, 28(1), 2017, pp. 229-244.

[31] Augustine, S., B. Payne, F. Sencindiver, and S. Woodcock, "Agile project management", Communications of the ACM, 48(12), 2005, pp. 8589.

[32] Scott-Young, C.M., M. Georgy, and A. Grisinger, "Shared leadership in project teams: An integrative multi-level conceptual model and research agenda", International Journal of Project Management, 37(4), 2019, pp. 565-581.

[33] Thorpe, R., J. Gold, and J. Lawler, "Locating Distributed Leadership", International Journal of Management Reviews, 13(3), 2011, pp. 239-250.

[34] Venkatesh, V., S. Brown, and H. Bala, "Bridging the Qualitative-Quantitative Divide", MIS Quarterly, 37(1), 2013, pp. 21-54.

[35] Yin, R.K., "Case study methods", in APA handbook of research methods in psychology, Vol 2: Research designs: Quantitative, qualitative, neuropsychological, and biological, H. Cooper, P.M. Camic, D.L. Long, A.T. Panter, D. Rindskopf, and K.J. Sher, Editors. 2012. American Psychological Association: Washington.

[36] Eseryel, U.Y. and D. Eseryel, "Action-embedded transformational leadership in self-managing global information systems development teams", The Journal of Strategic Information Systems, 22(2), 2013, pp. 103-120.

[37] Hazzan, O. and Y. Dubinsky, eds., Agile Anywhere, Springer International Publishing, Cham, 2014.

[38] Hoda, R., J. Noble, and S. Marshall, "Supporting Selforganizing Agile Teams", in Agile Processes in Software Engineering and Extreme Programming, A. Sillitti, O. Hazzan, E. Bache, and X. Albaladejo, Editors. 2011. Springer Berlin Heidelberg: Berlin, Heidelberg.

[39] Tripp, J., J. Saltz, and D. Turk, "Thoughts on Current and Future Research on Agile and Lean: Ensuring Relevance and Rigor", in Proceedings of the 51st Hawaii International Conference on System Sciences 2018.

[40] Tuckman, B.W., "Developmental Sequence in Small Groups", Psychological bulletin, 63, 1965, pp. 384399.

[41] Przybilla, L. and M. Wiesche, "Investigating the Performance Effects of Diversity Faultlines in IT Project Teams", in International Conference on Information Systems, (ICIS), Editor. 2019. 